\title{
NILAI TAMBAH DAN STRATEGI PENGEMBANGAN DI AGROINDUSTRI TEPUNG TAPIOKA X DI KECAMATAN KALIREJO KABUPATEN LAMPUNG TENGAH
}

\author{
(Added-Value Analysis and Development Strategy in Tapioca flour Agro-industry X in Kalirejo Sub-District \\ of Central Lampung)
}

Dwi Maulita, Wuryaningsih Dwi Sayekti, Wan Abbas Zakaria

Jurusan Agribisnis, Fakultas Pertanian, Universitas Lampung, Jl. Prof. Dr. Soemantri Brojonegoro No. 1

Bandar Lampung 35145, Telp.082376213881, e-mail: wuryaningsih.dwisayekti@fp.unila.ac.id

\begin{abstract}
The purposes of this research are to analyze the added value of tapioca flour, identifying the internal and external environment, and formulate development strategies of tapioca flour agroindustry X in Kalirejo SubDistrict. The research method is a case study and data used are primary and secondary data. The data are analyzed by using descriptive qualitative and quantitative analysis. The results showed that tapioca flour agroindustry X provided added value of IDR4,475.03/kg of tapioca flour $(63.28 \%)$ in grade A; IDR4,084.74/ kg of tapioca flour (61.16 \%) in grade B; and IDR2,897.05/kg of tapioca flour (52.67\%) in grade $C$. The internal environment which is the strength of tapioca flour agroindustry $X$ is a quality tapioca flour product and the weakness is the unskilled agro-industry workforce. The external environment which is the opportunity for tapioca flour agroindustry $X$ is technology and the threat is the high product competitiveness. Strategies of tapioca flour agroindustry X are as follows: (a) utilizing quality tapioca flour products to meet consumer demand, (b) utilizing the existence of modern technology by conducting training for workers, (c) increasing the availability of materials standards to meet technological capacity in production, (d) increasing cooperation with suppliers of raw materials to overcome the shortage of raw materials due to the large number of competitors in the same business, and (e) increasing business profits by maximizing the use of technology.
\end{abstract}

Key words: added-value, development strategy, internal and external environment, tapioca flour.

\section{PENDAHULUAN}

Singkong merupakan salah satu komoditas tanaman pangan jenis umbi-umbian yang banyak dibudidayakan di Indonesia khususnya Provinsi Lampung. Singkong mempunyai potensi produksi tinggi dan prospek yang baik. Tingginya produksi tanaman singkong didukung dengan kemudahan budidaya dan pertumbuhan tanaman singkong tergolong cepat yaitu berkisar antara 6 sampai 8 bulan (Purwono dan Purnawati 2007). Meskipun produksi tanaman singkong tinggi, namun tidak diikuti dengan harga jual singkong. Singkong merupakan komoditas tanaman pangan yang mempunyai fluktuasi harga jual yang tinggi menurut data Badan Pusat Stastistik (BPS) (2016). Tingginya fluktuasi harga singkong menyebabkan rendahnya pendapatan petani singkong. Umumnya singkong di jual tanpa diolah sehingga menyebabkan harga jual rendah. Hal ini menunjukkan bahwa pengolahan singkong menjadi produk lain semakin penting untuk dilakukan.

Agroindustri adalah industri yang mengolah komoditas pertanian primer menjadi produk olahan baik produk antara (intermediate product) maupun produk akhir (finish product) (Direktorat Jendral Bina Pengolahan dan Pemasaran Hasil Pertanian Departemen Pertanian (Ditjen BPPHP) 2002). Agroindustri yang menjadi unggulan dalam pengolahan singkong adalah agroindustri tepung tapioka. Agroindustri tepung tapioka yang ada di Provinsi Lampung pada tahun 2016 berjumlah 94 unit, dari total tersebut 48 unit berada di Kabupaten Lampung Tengah.

Penelitian ini difokuskan di Kabupaten Lampung Tengah khususnya di Kecamatan Kalirejo. Meskipun secara produksi Kecamatan Kalirejo tidak menempati urutan teratas, tetapi secara produktivitas Kecamatan Kalirejo merupakan kecamatan dengan produktivitas tertinggi di Kabupaten Lampung Tengah (BPS Kabupaten Lampung Tengah 2015). Salah satu agroindustri tepung tapioka yang masih berproduksi secara aktif di Kecamatan Kalirejo Kabupaten Lampung Tengah yaitu agroindustri tepung tapioka X. Agroindustri tepung tapioka $X$ di Kecamatan Kalirejo mengolah tepung tapioka yang terbagi atas tiga grade, grade $\mathrm{A}$ dan grade $\mathrm{B}$ yang 
dikeringkan menggunakan oven dan grade $\mathrm{C}$ menggunakan sinar matahari. Perbedaan grade tepung tapioka di agroindustri tepung tapioka $\mathrm{X}$ menyebabkan perbedaan harga jual dan fungsi tepung tapioka tersebut. Agroindustri tepung tapioka $\mathrm{X}$ yang ada di Kecamatan Kalirejo mempunyai perbedaan dibandingkan dengan agroindustri tepung tapioka yang lain yaitu pada pangsa pasar agroindustri. Pangsa pasar agroindustri tepung tapioka $\mathrm{X}$ adalah pasar industri tekstil dan industri pakan ternak, sedangkan agroindustri lain pangsa pasarnya adalah industri makanan, sehingga ini menarik untuk dikaji.

Berdasarkan ke tiga grade yang dilakukan di Agroindustri tepung tapioka $\mathrm{X}$ maka penting untuk dilakukan perbandingan mengenai nilai tambah tepung tapioka baik secara analisis usaha maupun secara strategi pengembangan usaha. Analisis nilai tambah penting untuk dilakukan sebagai tolak ukur dalam agroindustri untuk mengetahui seberapa besar tingkat nilai tambah yang dihasilkan dari pengolahan singkong menjadi tepung tapioka, sementara strategi pengembangan dianalisis untuk merumuskan strategi terbaik yang dapat diterapkan oleh agroindustri untuk mengembangkan usahanya.

Berdasarkan uraian tersebut maka tujuan penelitian ini adalah untuk mengetahui berapa nilai tambah dari pengolahan singkong menjadi tepung tapioka, mengidentifikasi lingkungan internal dan lingkungan eksternal, dan merumuskan strategi terbaik untuk mengembangkan agroindustri tepung tapioka X di Kecamatan Kalirejo Kabupaten Lampung Tengah.

\section{METODE PENELITIAN}

Penelitian ini dilakukan dengan menggunakan metode studi kasus. Lokasi penelitian dilakukan di Agroindustri Tepung Tapioka X di Kecamatan Kalirejo Kabupaten Lampung Tengah, yang dipilih dipilih secara sengaja atau purposive dengan pertimbangan bahwa Lampung Tengah mempunyai jumlah agroindustri tepung tapioka terbanyak dan agroindustri tepung tapioka $\mathrm{X}$ merupakan agroindustri yang membagi produk tepung tapioka dalam tiga grade. Pengumpulan data dilakukan pada bulan Maret sampai bulan Mei 2019. Data yang digunakan adalah data primer dan data sekunder. Data primer diperoleh dari pengamatan langsung dan wawancara menggunakan kuesioner sedangkan data sekunder diperoleh dari penelitian terdahulu, data agroindustri, dan instansi terkait. Responden penelitian ini adalah pemilik agroindustri, tenaga kerja tetap, dan tenaga kerja harian lepas. Data sekunder merupakan data pendukung untuk penelitian yang didapatkan dari penelitian terdahulu, jurnal, penelusuran pustaka, serta laporan dari instansi pemerintahan terkait seperti Badan Pusat Stastika Kabupaten Lampung Tengah dan data internal usaha tepung tapioka.

Untuk menjawab tujuan pertama dalam penelitian ini yaitu menganalisis tingkat nilai tambah dari pengolahan singkong digunakan analisis diskriptif kuantitatif. Metode yang digunakan dalam perhitungan nilai tambah adalah metode Hayami, (1987) yang dapat dilihat pada Tabel 1. Metode ini juga digunakan pada penelitian Maharani, Lestari, dan Kasymir (2013) pada pengolahan limbah padat ubi kayu (onggok). Untuk perhitungan biaya dihitung menggunakan metode alokasi joint cost.

Analisis usaha di Agroindustri tepung tapioka X menggunakan metode alokasi joint cost dikarenakan agroindustri tepung tapioka $\mathrm{X}$ menggunakan biaya bersama untuk menghasilkan tiga grade produk. Menurut Mulyadi (2005) alokasi joint cost merupakan metode yang digunakan untuk mengitung biaya bersama dalam suatu produk. Perhitungan biaya menggunakan metode alokasi joint cost digunakan apabila biaya yang digunakan dalam suatu produk tidak diketahui secara pasti jumlah dan besarannya. Alokasi joint cost diperoleh dengan cara membagi hasil produksi dari produk disetiap grade dengan total produksi untuk keseluruhan grade. Alokasi joint cost dapat dihitung menggunakan rumus sebagai berikut :

$\frac{\mathrm{Q} a \ldots \ldots . . .(\mathrm{c})}{\sum \mathrm{Q}(\mathrm{a}-\mathrm{c})}$

Keterangan:

Qa

$\sum \mathrm{Q}(\mathrm{a}-\mathrm{c}) \quad$ :Total produk jenis a sampai c

Metode analisis data yang digunakan dalam strategi pengembangan agroindustri tepung tapioka $X$ di Kecamatan Kalirejo Kabupaten Lampung Tengah adalah analisis diskriptif kualitatif menggunakan analisis SWOT. Metode ini juga digunakan oleh Rizky, Haryono, dan Kasymir (2016) tentang strategi pengembangan ubi kayu. 
Tabel 1. Kerangka perhitungan metode Hayami

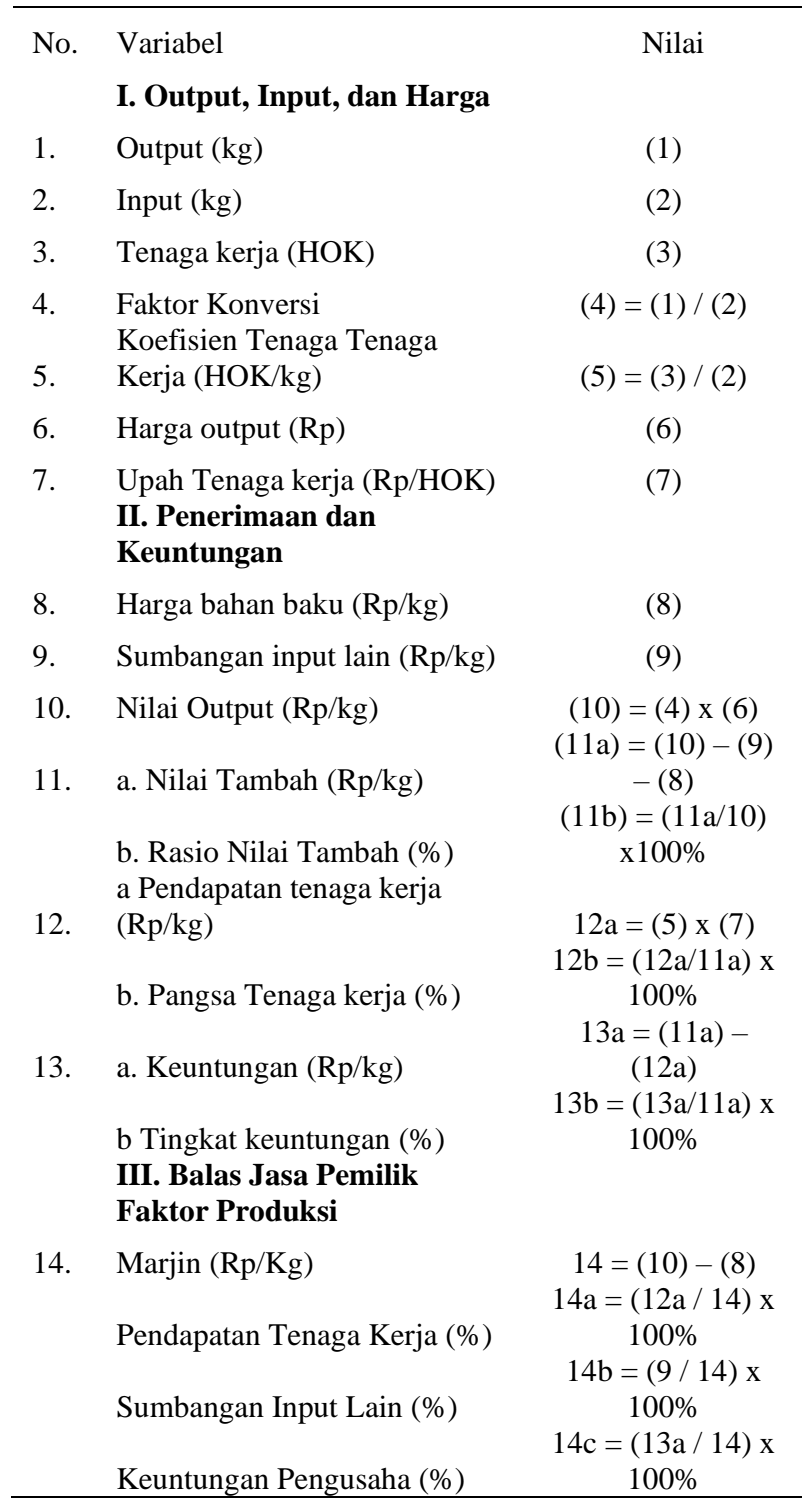

Sumber : Hayami (1987)

Menurut Rangkuti (2006) matriks IFE (Internal Factor Evaluation) digunakan untuk mengidentifikasi dan mengevaluasi faktor-faktor internal yang menjadi kekuatan dan kelemahan pada pengembangan usaha tepung tapioka seperti SDM, lokasi usaha, pemasaran, produksi, manajemen dan keuangan. Menurut Soekartawi (2000) matriks EFE (Eksternal Factor Evaluation) berfungsi untuk mengidentifikasi peluang dan ancaman bagi pengembangan usaha tepung tapioka. Faktor eksternal tersebut yaitu teknologi, pasar, pesaing, dan kondisi alam.

Tahapan dalam perumusan strategi pengembangan usaha agroindustri tepung tapioka setelah dilakukan analisis matriks EFAS dan IFAS adalah memetakan hasil analisis ke dalam kuadran SWOT yang dapat dilihat pada Gambar 1. Pada diagram
SWOT terdapat empat kuadran yaitu kuadran I adalah Growth, kuadran II adalah diversifikasi, kuadran III adalah turn arround, dan kuadran IV adalah defensif.

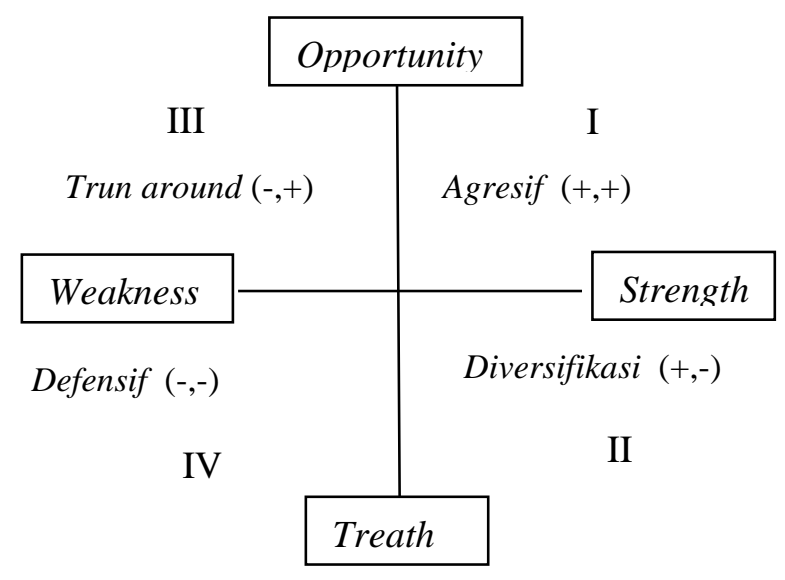

Gambar 1. Diagram SWOT

Matriks SWOT digunakan untuk merumuskan alternatif strategi yang dihasilkan dari penyilangan empat sel kemungkinan alternatif strategi, yaitu strategi kekuatan-peluang (S-O), strategi kelemahan-peluang (W-O), strategi kelemahanancaman (W-T), dan strategi kekuatan-ancaman (S-T) (Rangkuti 2006).

Setelah tahapan-tahapan terdahulu dibuat dan dianalisa, maka tahap selanjutnya disusunlah daftar prioritas yang harus diimplementasikan. Quantitative Strategic Planning Matrix (QSPM ) merupakan teknik yang secara obyektif dapat menetapkan strategi altematif yang diprioritaskan. metode analisis diskriptif-kualitatif.

\section{HASIL DAN PEMBAHASAN}

Agroindustri tepung tapioka $\mathrm{X}$ merupakan agroindustri kelas menengah yang ada di Kabupaten Lampung Tengah. Agroindustri tepung tapioka X berdiri pada tahun 1980 -an, dan sampai dengan saat ini telah mengalami tiga kali perpindahan kepemilikan. Agroindustri tepung tapioka $\mathrm{X}$ merupakan agroindustri yang membagi produk tepung tapioka menjadi tiga grade. Hasil penelitian menunjukkan bahwa bahan baku utama yang digunakan dalam mengolah tepung tapioka adalah singkong dengan varietas kasetsrat, yang berasal dari Kecamatan Padang Ratu Kabupaten Lampung Tengah dengan jumlah dan waktu pembelian disesuaikan kebutuhan dan hasil dari produksi di daerah tersebut. Harga bahan baku bersifat fluktuatif, pada saat penelitian dilakukan 
harga bahan baku singkong per $\mathrm{kg}$ sebesar Rp1.300,00. Modal awal dalam menjalankan usaha agroindustri tepung tapioka $\mathrm{X}$ dihitung berdasarkan modal terakhir yang dikeluarkan oleh pemilik ke tiga dari agroindustri tepung tapioka $X$ dengan jumlah sebesar satu milyar rupiah. Tenaga kerja agroindustri tepung tapioka $\mathrm{X}$ berasal dari masyarakat sekitar agroindustri.

\section{Biaya}

Biaya yang digunakan dalam penelitian ini adalah biaya produksi, biaya penyusutan peralatan, dan biaya tenaga kerja. Rata-rata biaya produksi sebesar Rp18.126.898 per produksi. Total biaya penyusutan peralatan sebesar Rp593.382,12 per produksi. Biaya produksi dan penyusutan peralatan tersebut kemudian dialokasikan menggunakan alokasi joint cost dikarenakan biaya tersebut digunakan secara bersama-sama untuk menghasilkan tiga produk. Sementara untuk biaya tenaga kerja tidak dilakukan perhitungan joint cost dikarenakan telah dibagi per kegiatan pada masingmasing grade. Berdasarkan perhitungan yang telah dilakukan diperoleh alokasi joint cost pada masing-masing grade $\mathrm{A}, \mathrm{B}$, dan $\mathrm{C}$ sebesar 0,42 0,36 , dan 0,22 . Perhitungan ini diperoleh dari membagikan antara total produksi pada masingmasing grade dibagi dengan total produksi untuk seluruh grade. Biaya penyusutan peralatan untuk masing-masing grade adalah sebesar Rp248.141,61 untuk grade A, Rp212.179,06 untuk grade B, dan Rp133.061,45 untuk grade C. Hasil perhitungan tenaga kerja diperoleh rata-rata untuk masing-masing grade $\mathrm{A}, \mathrm{B}$, dan $\mathrm{C}$ sebesar 0,75 HOK/produksi, 0,32 HOK/produksi, dan 0,45 HOK/produksi. Harga jual tepung tapioka pada masing-masing grade $\mathrm{A}, \mathrm{B}$, dan $\mathrm{C}$ adalah sebesar Rp9.000,00/kg, Rp8.500,00/kg, dan Rp7.000/kg.

\section{Analisis Nilai Tambah}

Berdasarkan hasil perhitungan menggunakan metode Hayami diperoleh dasar perhitungan nilai tambah dengan penggunaan bahan baku rata-rata per produksi untuk masing-masing grade $\mathrm{A}, \mathrm{B}$, dan $\mathrm{C}$ adalah sebesar $21.954,55 / \mathrm{kg}, 18.772,73 / \mathrm{kg}$, dan $11.772,73 / \mathrm{kg}$. Hasil output rata-rata untuk masingmasing grade $\mathrm{A}, \mathrm{B}$, dan $\mathrm{C}$ adalah sebesar 17.250 $\mathrm{kg} /$ produksi, $14.750 \mathrm{~kg} /$ produksi, dan 9.250 $\mathrm{kg} /$ produksi. Berdasarkan penelitian dan perhitungan yang telah dilakukan diperoleh nilai tambah tepung tapioka pada garde $\mathrm{A}, \mathrm{B}$, dan $\mathrm{C}$ berturut-turut adalah sebesar Rp4.475,03 Rp4.084,74, dan Rp2.897,05 yang artinya untuk setiap $1 \mathrm{~kg}$ singkong seharga $\mathrm{Rp} 1.300,00$ akan menghasilkan nilai tambah pada garde $\mathrm{A}, \mathrm{B}$, dan $\mathrm{C}$ berturut-turut adalah sebesar Rp4.475,03, Rp4.084,74 dan Rp2.987,05.

Berdasarkan kriteria penilaian nilai tambah, yaitu NT > 0, maka berarti pengembangan agroindustri tepung tapioka memberikan nilai tambah yang positif. Pengolahan tepung tapioka telah memberikan nilai tambah terhadap singkong sebesar 63,28 persen untuk grade A, 61,16 persen untuk grade B, dan 52,67 persen untuk grade C. Artinya untuk setiap Rp100,00 nilai produk akan diperoleh nilai tambah pada masing-masing grade sebesar Rp63,28, Rp61,16, dan Rp52,67. Berdasarkan hasil dari perhitungan tersebut maka dapat ditarik satu kesimpulan bahwa agroindustri tepung tapioka $\mathrm{X}$ layak untuk terus dikembangkan dimasa depan. Nilai tambah pada pengolahan tepung tapioka dapat terus dikembangkan apabila dilakukan pengembangan secara terus-menerus pada proses produksi tepung tapioka.

Hasil perhitungan nilai tambah di agroindustri tepung tapioka $\mathrm{X}$ di Kecamatan Kalirejo Kabupaten Lampung Tengah sejalan dengan penelitian Imani (2016) yang menghasilkan perhitungan nilai tambah singkong yang bernilai positif di mana perhitungan tersebut sama dengan hasil perhitungan pada nilai tambah agroindustri tepung tapioka $\mathrm{X}$ yang memperoleh nilai positif.

\section{Analisis Lingkungan Internal}

Lingkungan internal yang menjadi kekuatan di agroindustri tepung tapioka adalah produk, dimana produk yang dihasilkan oleh agroindustri tepung tapioka X merupakan produk yang berkualitas dengan perolehan rata-rata bobot sebesar 0,15 dan rating 3. Bobot dihitung dari menjumlahkan hasil dari penilaian responden terhadap komponen internal kemudian dijumlahkan dan dihitung rataratanya, dimana nilai bobot berkisar dari 0 sampai 2 , dengan ketentuan nilai 0 diberikan apabila faktor horizontal tidak kalah penting dengan faktor vertikal, nilai 1 diberikan apabila faktor horizontal sama penting dengan faktor vertikal dan nilai 2 diberikan apabila faktor horizontal lebih penting dari faktor vertikal. Untuk lingkungan internal yang menjadi kelemahan adalah tenaga kerja, dalam hal ini tenaga kerja yang ada di agroindustri tepung tapioka $\mathrm{X}$ merupakan tenaga kerja yang kurang terampil dengan perolehan bobot 0,26 dan ranking 1. 


\section{Analisis Lingkungan Eksternal}

Lingkungan eksternal yang menjadi peluang di agroindustri tepung tapioka $\mathrm{X}$ adalah teknologi, dimana teknologi yang digunakan oleh agroindustri tepung tapioka $\mathrm{X}$ merupakan teknologi yang cukup modern dengan perolehan rata-rata bobot sebesar 0,66 dan rating 3 . Sementara untuk lingkungan eksternal yang menjadi ancaman adalah pesaing, yaitu pesaing dalam satu usaha yang sama dengan bobot 0,25 dan ranking 2 .

\section{Strategi Pengembangan Agroindustri Tepung Tapioka}

Lingkungan merupakan salah satu aspek yang terpenting dalam suatu agroindustri. Lingkungan agroindustri mencakup pada semua faktor yang dapat mempengaruhi keberhasilan dan pencapaian tujuan yang telah ditetapkan oleh agroindustri. Analisis ini akan memberikan gambaran tentang keadaan agroindustri yang biasanya disederhanakan dengan sebutan SWOT (Strengths, Weaknesses, Opportunities, dan Threats) yang dimiliki oleh agroindustri. Analisis lingkungan internal akan memberikan gambaran tentang kekuatan dan kelemahan dari agroindustri (SW). Sementara analisis lingkungan eksternal akan memberikan gambaran tentang peluang dan ancaman (OT) yang dimiliki oleh agroindustri.

Kekuatan di bidang produksi menunjukkan bahwa kualitas produk yang dihasilkan oleh agroindustri tepung tapioka $\mathrm{X}$ mempunyai kualitas yang baik dan mampu bersaing dengan produk-produk sejenis. Sementara kelemahan yang paling besar yang dimiliki oleh agroindustri tepung tapioka $X$ adalah lokasi usaha yang tidak strategis.

Tabel 2. Matrik faktor internal

\begin{tabular}{|c|c|c|c|c|c|}
\hline \multirow[t]{2}{*}{ No. } & $\begin{array}{c}\text { Faktor } \\
\text { Internal } \\
\end{array}$ & \multirow[t]{2}{*}{ Bobot } & \multirow[t]{2}{*}{ Rating } & \multirow[t]{2}{*}{ Skor } & \multirow[t]{2}{*}{ Ranking } \\
\hline & Kekuatan & & & & \\
\hline 1. & $\begin{array}{l}\text { Produk tepung } \\
\text { tapioka }\end{array}$ & 0,15 & 3 & 0,45 & 1 \\
\hline 2. & Bahan baku & 0,13 & 3 & 0,4 & 2 \\
\hline 3. & Pemasaran & 0,14 & 2 & 0,28 & 3 \\
\hline \multicolumn{6}{|c|}{ Kelemahan } \\
\hline 4. & Lokasi usaha & 0,13 & 1 & 0,13 & 3 \\
\hline 5. & $\begin{array}{l}\text { Tenaga kerja } \\
\text { Keuntungan }\end{array}$ & 0,26 & 1 & 0,26 & 1 \\
\hline \multirow[t]{2}{*}{6.} & usaha & 0,18 & 1 & 0,18 & 2 \\
\hline & Total & 1 & & 1,71 & \\
\hline
\end{tabular}

Tabel 3. Matrik faktor eksternal

\begin{tabular}{|c|c|c|c|c|c|}
\hline \multirow[t]{2}{*}{ No. } & $\begin{array}{c}\text { Faktor } \\
\text { Eksternal }\end{array}$ & \multirow[t]{2}{*}{ Bobot } & \multirow[t]{2}{*}{ Rating } & \multirow[t]{2}{*}{ Skor } & \multirow[t]{2}{*}{ Ranking } \\
\hline & Peluang & & & & \\
\hline 1. & $\begin{array}{l}\text { Permintaan } \\
\text { konsumen }\end{array}$ & 0,2 & 3 & 0,61 & 2 \\
\hline \multirow[t]{2}{*}{3.} & $\begin{array}{l}\text { Teknologi } \\
\text { Posisi tawar } \\
\text { bahan baku }\end{array}$ & 0,22 & 2 & 0,66 & 3 \\
\hline & \multicolumn{5}{|l|}{ Ancaman } \\
\hline 4. & $\begin{array}{l}\text { Peran } \\
\text { kebijakan } \\
\text { pemerintah }\end{array}$ & 0,16 & 1 & 0,16 & 2 \\
\hline 5. & $\begin{array}{l}\text { Pesaing } \\
\text { Iklim dan }\end{array}$ & 0,13 & 2 & 0,25 & 1 \\
\hline 6. & cuaca & 0,14 & 1 & 0,14 & 3 \\
\hline & Total & 1 & & 2,12 & \\
\hline
\end{tabular}

Berdasarkan Tabel 3 diketahui bahwa peluang yang paling besar yang dimiliki agroindustri tepung tapioka adalah teknologi yang memadai, dimana dalam menjalankan usahanya agroindustri tepung tapioka $\mathrm{X}$ telah menerapkan teknologi yang modern, sehingga dapat dijadikan peluang untuk meningkatkan kualitas dan kuantitas dari produk tepung tapioka. Sementara untuk bagian ancaman yang paling besar adalah daya saing produk tinggi, karena akan berpengaruh pada tingkat penjualan produk dan berpengaruh pada keberlangsungan agroindustri. Berdasarkan nilai skor faktor internal dan faktor eksternal agroindustri tepung tapioka, maka dibuat diagram SWOT dengan cara menjumlahkan skor faktor internal dan eksternal kemudian dari keduanya dihitung selisih yaitu total skor kekuatan dikurangi dengan total skor kelemahan dan total skor peluang dikurangi dengan total skor ancaman. Pembobotan diagram SWOT dapat dilihat pada Tabel 4.

Tahapan selanjutnya setelah dihitung selisih dari faktor internal dan faktor eksternal maka dibuat diagram SWOT pada agroindustri tepung tapioka $\mathrm{X}$ yang dapat dilihat pada Gambar 2 .

Tabel 4. Pembobotan diagram SWOT

\begin{tabular}{lcccc}
\hline \multirow{2}{*}{ Uraian } & \multicolumn{2}{c}{ Faktor Internal } & \multicolumn{2}{c}{ Faktor Eksternal } \\
\cline { 2 - 5 } & Kekuatan & Kelemahan & Peluang & Ancaman \\
\hline Bobot $\mathrm{x}$ & \multirow{2}{*}{0,13} & 0,57 & 1,58 & 0,55 \\
Rating & 1,13 & \multicolumn{2}{c}{1,03} & \\
Selisih & & 0,56 & &
\end{tabular}


Berdasarkan diagram SWOT diketahui bahwa agroindustri tepung tapioka $\mathrm{X}$ berada pada kuadran I yang artinya berada pada situasi yang sangat menguntungkan bagi agroindustri dikarenakan agroindustri tepung tapioka dapat mengembangk usahanya dengan memanfaatkan kekuatan dan peluang yang dimiliki oleh agroindustri. Pencapaian strategi dapat dilakukan dengan peningkatan kualitas menggunakan teknologi yang modern dan memenuhi permintaan pasar akan tepung tapioka. Berikut adalah gambar dari diagram SWOT lingkungan internal dan lingkungan eksternal.

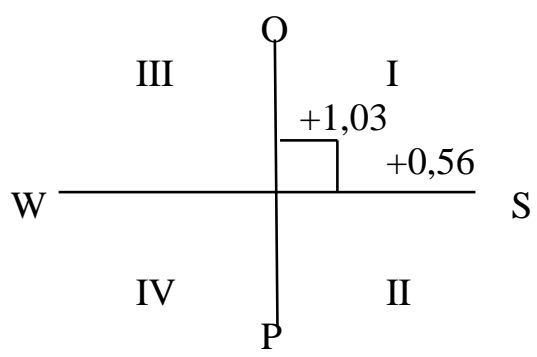

Gambar 2. Diagram SWOT

Penelitian lain yang dilakukan oleh Ariesta, Lestari, dan Sayekti (2016) pada agroindustri beras siger dan Prabowo, Haryono, dan Affandi (2015) pada usahatani ubi kayu yang menyatakan bahwa agroindustri berada pada kuadran II, yang artinya agroindustri berada pada situasi yang cukup menguntungkan namun masih terdapat beberapa tantangan di mana agroindustri berada pada kondisi pertumbuhan yang kuat namun menghadapi tantangan yang besar, hasil ini berbeda dari penelitian yang dilakukan di agroindustri tepung tapioka $\mathrm{X}$ yang berada pada kuadran I.

\section{Analisis Strategi Agroindustri Tepung Tapioka}

Langkah dalam analisis strategi adalah menuliskan dan mengidentifikasikan strategi alternatif yang harus dipertimbangkan agroindustri, selanjutnya mencatat strategi tersebut atas baris QSPM, lalu menetapkan AS (attractiveness score), yaitu nilai yang menunjukkan kemenarikan relatif untuk masing-masing strategi yang terpilih. Batasan nilai AS adalah 1 sampai 4 . Nilai $1=$ tidak menarik, $2=$ agak menarik, 3 = secara logis menarik, $4=$ sangat menarik. Setelah diperoleh AS kemudian menghitung TAS (total attractiveness score) dari hasil perkalian bobot yang terdapat pada matrik IFE dan EFE dengan AS yang diperoleh. TAS menunjukkan kemenarikan relatif dari masing- masing alternatif strategi. Penjumlahan TAS pada masing-masing kolom QSPM didasarkan pada nilai TAS yang di dapat, nilai TAS dari alternatif strategi yang tertinggi menunjukkan bahwa alternatif strategi itu menjadi pilihan utama. Strategi prioritas yang dihasilkan nantinya diharapkan dapat membantu agroindustri dalam mengembangkan.

Berdasarkan analisis diperoleh 10 strategi prioritas yang dapat dikembangkan di agroindustri tepung tapioka $\mathrm{X}$ yang telah disesuaikan dengan visi dan misi perusahaan serta berdasarkan perhitungan QSPM. Sepuluh strategi prioritas adalah 1) meningkatkan kualitas produk tepung tapioka dengan teknologi yang modern, 2) meningkatkan ketersediaan bahan baku untuk memenuhi kapasitas teknologi dalam berproduksi, 3) memanfaatkan produk tepung tapioka yang berkualitas untuk memenuhi permintaan konsumen, 4) memanfaatkan adanya teknologi yang modern dengan mengadakan pelatihan bagi tenaga kerja, 5) meningkatkan keuntungan usaha dengan memaksimalkan penggunaan teknologi, 6) menambah kerjasama dengan pemasok bahan baku untuk mengatasi kekurangan bahan baku akibat banyaknya pesaing di dalam usaha yang sama, 7) menambah jaringan pemasaran dengan lembaga pemerintahan, 8) meningkatkan pemberdayaan SDM dengan menyediakan pendamping produksi, 9) menambah kerjasama dengan pemasok bahan baku untuk mengatasi kekurangan bahan baku akibat banyaknya pesaing di dalam usaha yang sama, dan 10) meningkatkan keterampilan tenaga kerja untuk menghasilkan produk yang mampu bersaing dengan produk sejenis.

\section{KESIMPULAN}

Agroindustri tepung tapioka $\mathrm{X}$ memberikan nilai tambah pada masing-masing grade $\mathrm{A}$, grade $\mathrm{B}$, dan grade $\mathrm{C}$ sebesar 63,28 persen, 61,16 persen, dan 52,67 persen, lingkungan internal yang menjadi kekuatan bagi agroindustri tepung tapioka $\mathrm{X}$ adalah produk tepung tapioka yang berkualitas dan yang menjadi kelemahan adalah tenaga kerja yang kurang terampil. Lingkungan eksternal yang menjadi peluang bagi agroindustri tepung tapioka $\mathrm{X}$ adalah teknologi yang memadai dan yang menjadi ancaman adalah daya saing produk yang tinggi. Strategi pengembangan agroindustri tepung tapioka $X$ adalah 1) meningkatkan ketersediaan bahan baku untuk memenuhi kapasitas teknologi dalam berproduksi, 2) memanfaatkan adanya teknologi yang modern dengan mengadakan 
pelatihan bagi tenaga kerja, 3) memanfaatkan produk tepung tapioka yang berkualitas untuk memenuhi permintaan konsumen, 4) meningkatkan keterampilan tenaga kerja untuk menghasilkan produk yang mampu bersaing dengan produk sejenis, 5) meningkatkan kualitas produk tepung tapioka dengan teknologi yang modern.

\section{DAFTAR PUSTAKA}

Ariesta W, Lestari DAH, dan Sayekti WD. 2016. Perilaku konsumen dan strategi pengembangan Agroindustri Beras Siger Tunas Baru Di Kelurahan Pinang Jaya Kemiling Kota Bandar Lampung. JIIA, 4 (3): 326-334.

http://jurnal.fp.unila.ac.id/index.php/JIA/article/vie w/1508/1362. [5 Mei 2019].

BPS [Badan Pusat Stastistik]. 2017. Harga Jual Singkong di Provinsi Lampung Tahun 2016. BPS. Lampung. https://lampung.bps.go.id/dynamictable/2017/ 06/20/402/harga-produsen-ketela-pohon-rp100kg-2016.html. [5 Mei 2019].

. 2016. Luas Panen dan Produksi Singkong di Kabupaten Lampung Tengah Tahun 2015. BPS. Lampung. https://lampungtengahkab.bps.go.id/statictable /2015/05/06/34/luas-panen-tanaman-ubi-kayumenurut-kecamatan-ha-2012---2014.html. [5 Mei 2019].

[Direktorat Jenderal Bina Pengolahan dan Pemasaran Hasil Pertanian Departemen Pertanian Republik Indonesia dan Kepala Bagian Urusan Logistik]. 2002. Keputusan Bersama Direktorat Jenderal Bina Pengolahan dan Pemasaran Hasil Pertanian

Departemen Pertanian Republik Indonesia dan Kepala Bagian Urusan Logistik. http://www.bulog.go.id/pers/skb_q_2003.pdf[ 5 Desember 2018].
Hayami. 1987. Agricultural Marketing and Processing in Upland Java. A Perspective From a Sunda Village, CGPRT. Bogor.

Imani I. 2016. Analisis keuntungan dan nilai tambah pengolahan ubikayu (manihot esculenta). Universitas Haluoleo. https://docplayer.info/99300956-Skripsianalisis-keuntungan-dan-nilai-tambahpengolahan-ubikayu.html. [5 Mei 2019].

Maharani CND, Lestari DAH, dan Kasymir E. 2013. Nilai tambah dan kelayakan usaha skala kecil dan skala menengah pengolahan limbah padat ubi kayu onggok di Kecamatan Pekalongan Kabupaten Lampung Timur. JIIA, 1 (4) : 284-290. http://jurnal.fp.unila.ac.id/index.php/JIA/articl e/view/704/646. [5 Mei 2019].

Mulyadi. 2005 Akuntansi biaya edisi kelima yokyakarta UPPAMP YKPN Universitas Gajah Mada.

Prabowo IWHB, Haryono D, dan Affandi MI. 2015. Strategi pengembangan usahatani ubi kayu (manihot utilissima) di Kecamatan Menggala. JIIA 3 (1). 48-56. http://jurnal.fp.unila.ac.id/index.php/JIA/articl e/view/1017/922. Diakses pada 5 Mei 2019.

Purwono dan Purnawati H. 2007. Budidaya 8 Jenis Tanaman Pangan Unggul. Penebar Swadaya. Jakarta.

Rangkuti F. 2006. Teknik Mengukur dan Strategi Meningkatkan Kepuasan Pelanggan. Penerbit PT Gramedia Pustaka Utama. Jakarta.

Rizky A, Haryono D, dan Kasymir E. 2016. Analisis usaha dan strategi pengembangan ternak kalkun mitra alam Kabupaten Pringsewu. JIIA, 4 (3) : 235-242. http://jurnal.fp.unila.ac.id/index.php/JIA/articl e/view/1497/1351. [5 Mei 2019].

Soekartawi. 2000. Pengantar Agroindustri. PT Raja Grafindo Persada. Jakarta. 